\title{
Capsule Commentary on Jackson et al., The Quality of Written Feedback by Attendings of Internal Medicine Residents
}

\author{
Subha Ramani, MBBS, MMEd, MPH \\ Brigham and Women's Hospital, The Phyllis Jen Center for Primary Care, Harvard Medical School, Boston, MA, USA.
}

J Gen Intern Med 30(7):1003

DOI: $10.1007 / \mathrm{s} 11606-015-3258-\mathrm{x}$

() Society of General Internal Medicine 2015

$I^{n}$ n this retrospective study by Jackson et al., ${ }^{1} 500$ evaluations of internal medicine residents by their attending physicians were randomly selected (from 6,603 available evaluations), and the written feedback coded and categorized. Criteria for effective feedback developed by small groups were independently applied by group participants and investigators to rate the feedback as low, moderate, or high quality. Of 2,056 unique utterances, many were non-specific (29\%) or personality-related $(20 \%)$. The authors conclude that most written feedback comments are of moderate (65\%) or low (13\%) quality; only $22 \%$ were rated as high quality. Investigator ratings showed high interrater reliability; those from the groups did not. Higherquality comments tended to be more discriminating, and included lower ratings of residents over a greater range. Finally, negative written comments on medical knowledge correlated with lower in-service training scores.

Feedback is an important area for research in education. The strengths of this study include the development and application of criteria to rate the quality of written feedback, the large number of evaluations for analysis, and the use of mixed methods. To advance this field, it is important to examine feedback exchanges (verbal or written) and to design interventions that result in performance improvement. The feedback criteria developed by the groups do not differ significantly from those previously described. ${ }^{2,3}$ A limitation of this study is the focus on written comments on summative evalu- ations and correlation with in-service scores. Such comments reflect neither a formative feedback exchange between teachers and learners - especially when the evaluators are not provided with a structure or guidelines - nor the content and effectiveness of such conversations. ${ }^{4}$

For medical educators, some principles of feedback are worth emphasizing. Feedback is best exchanged within an institutional culture that emphasizes professional growth, encourages a feedback dialogue, focuses on observed behaviors, uses non-judgmental language of strengths and areas for improvement rather than positive/negative, and uses learning goals as the basis for feedback. ${ }^{4,5}$ The feedback loop is incomplete without self-reflection and action plans, especially in this era of competency-based education. ${ }^{4}$ Finally, feedback is best detached from evaluation, as the two are not synonymous. $^{3-5}$

Corresponding Author: Subha Ramani, MBBS, MMEd, MPH; Brigham and Women's Hospital, The Phyllis Jen Center for Primary CareHarvard Medical School, Boston, MA, USA (e-mail: sramani@partners.org).

\section{REFERENCES}

1. Jackson JL, Kay C, Jackson WC, Frank M. The quality of written feedback by attendings of internal medicine residents. J Gen Int Med. 2015. doi:10. 1007/s11606-015-3237-2.

2. Anderson PA. Giving feedback on clinical skills: are we starving our young? J Grad Med Educ. 2012;4:154-8.

3. van der Ridder JMM, Stokking KM, McGaghie WC, ten Cate OT. What is feedback in clinical education? Med Educ. 2008;42(2):189-97.

4. Boud D, Malloy E. Feedback in higher and professional education. Understanding it and doing it well. London and New York: Routledge, Taylor and Francis group; 2013: 1-33, 104-124.

5. Delva D, Sargeant J, Miller S, et al. Encouraging residents to seek feedback. Med Teach. 2013;35:e1625-e31.

Published online March 3, 2015 